\title{
Estimation of the lion (Panthera leo) population in the southwestern Kgalagadi Transfrontier Park using a capture-recapture survey
}

\author{
J.G. Castley ${ }^{\dagger}$, M.H. Knight' ${ }^{1}$ M.G.L. Mills ${ }^{2} \&$ C. Thouless ${ }^{3 \ddagger}$ \\ ${ }^{1}$ Conservation Services, South African National Parks, P.O. Box 20419, Humewood, Port Elizabeth, 6013 South Africa \\ E-mail: gcastley@upe.ac.za; mknight@upe.ac.za \\ ${ }^{2}$ Conservation Services, South African National Parks, Endangered Wildlife Trust, and Mammal Research Institute, \\ University of Pretoria, Private Bag X402, Skukuza, 1350 South Africa. E-mail: gusm@parks-sa.co.za \\ ${ }^{3}$ Department of Wildlife and National Parks, P.O. Box 131, Gaborone, Botswana.E-mail: thouless@africaonline.co.ke \\ Received 26 January 2001. Accepted 5 June 2001
}

\begin{abstract}
A previous estimate of the lion (Panthera leo) population in the southwestern Kgalagadi Transfrontier Park (KTP) was made over 20 years ago. This together with increased fears regarding the viability of the population as a result of recent killings of roaming animals, an observed increase in non-violent mortalities during 1996, and possible reduced genetic viability due to suspected isolation, prompted another investigation. Between October 1996 and December 1996, 68 lions were captured and marked and subjected to two recapture (resighting) samples. The minimum estimate derived from direct enumeration of marked and unmarked individuals is between 100-103 individuals. Assessment of the adult and subadult population using the Lincoln-Petersen estimator and the software program NOREMARK gives a figure between 92 and 125. The current estimate is below the previous estimate of between 113 and 140 lions. Lion densities of 1.2 adult and subadult lions/100 $\mathrm{km}^{2}$ in the semi-arid southern Kalahari are considerably lower than those in more mesic regions. Furthermore, there appears to be some demographic variability with the ratio of females to males being twice as high as that recorded 20 years ago.
\end{abstract}

Key words: Lincoln-Petersen, Kalahari, semi-arid, carnivore, population estimate, demography.

\section{INTRODUCTION}

The size of the lion (Panthera leo) population in the southwestern region of the Kgalagadi Transfrontier Park (KTP), formerly the Kalahari Gemsbok National Park (KGNP), was estimated at between 113 and 140 individuals in 1976, with an adult sex ratio of 1 male:1.8 females (Mills et al. 1978). There has been considerable recent interest in the survival of the population, driven largely by the ongoing persecution of the lions by neighbouring farmers who suffer occasional stock losses by roaming lions. Between April 1996 and December 1997, 40 lions were known to have left the southwestern Kgalagadi district, either along the western or southern KGNP or southern Gemsbok National Park (GNP) borders in Botswana. Of these, 23 (eight subadult males, one adult male, one adult female and 13 unidentified) were killed by neighbouring farmers, nine animals returned into the park of their own accord, while a further eight were tranquilized and returned to the park (Holt-Biddle 1996; N. du Plessis, pers. comm.).

${ }^{\dagger}$ Author for correspondence.

${ }^{\ddagger}$ Present address: P.O. Box 209, Timau, Kenya.
There was no indication that it was only a certain sector of the lion population that ventured out of the park as the same animals were not recorded on more than one occasion (N. du Plessis, pers. comm.), neither was there any indication as to what proportion these lions make up of the total number that venture outside the park boundaries.

Furthermore, changes in movement patterns and hence the distribution and density of major prey species, primarily gemsbok (Oryx gazella) and blue wildebeest (Connochaetes taurinus) (Mills 1984; Knight 1991; Verlinden 1998), may have influenced the size and distribution of the lion population. Contrary to earlier observations by Mills et al. (1978) that the highest density of larger herbivores of the dune habitats of the KGNP were found in the area to the west of the Auob River, recent aerial surveys have shown a shift in the distribution of these species, with the major concentrations found in the northern section of the KGNP and in the central region of the adjoining GNP, although there has been little change in the overall prey biomass (Castley \& Knight 1997, 1998). 
For these reasons it was decided to reassess the size of the lion population in 1996/7 using a capture-recapture technique similar to that used by Mills et al. (1978). In this paper we present the results of this survey, discuss the shortcomings of the method and ways to address them, as well as discuss some of the implications of the results.

\section{STUDY AREA}

The study was primarily conducted in the $9593 \mathrm{~km}^{2}$ southwestern KTP incorporating the previous KGNP of South Africa, and adjacent dune areas along the Nossob riverbed in the GNP (Fig. 1). Although the area is fenced with standard electrified game fencing on its western and southern borders, the larger predators, particularly lion and leopard (Panthera pardus) occasionally enter neighbouring properties (Mills et al. 1978; Bothma et al. 1998).

The KGNP is a semi-arid (average annual rainfall of $100 \mathrm{~mm}$ ), open savanna woodland and dune grassland landscape with the vegetation physiognomy determined by the rainfall gradient prevailing from the low-rainfall areas in the southwest, to the higher rainfall areas in the northeast (Bothma et al. 1994). The predominantly sandy areas are bisected by the important fossil Nossob and Auob river beds, the two most important habitats for ungulates in the southern Kalahari. Each of these river systems generally supports higher densities of large mammal species, although their use of these habitats varies (Knight 1991). This has been influenced by the provision of artificial waterholes (Knight et al. 1987), particularly in the case of blue wildebeest (Mills \& Retief 1984a), and periodic rainfall events (Mills \& Retief 1984b; Knight 1991). The distribution of these species has shifted recently (Castley \& Knight 1997, 1998) although there has been little change in the prey biomass (Fig. 2).

\section{METHODS}

As conventional census techniques for large mammals such as line transect ground counts and aerial surveys are unsuitable for low density, nocturnally active large carnivores (Mills 1996; Creel \& Creel 1997), this study used the LincolnPetersen method in a two sample capture-recapture experiment. During the capture phase, which took place between 22 October and 15 December 1996, 68 lions (47 females and 21 males) were permanently marked after chemical immobilization. All marked and non-marked animals were recorded in two subsequent recapture operations of approximately one month's duration (sensu Mills et al. 1978).

Lion-marking efforts covered the entire southwestern Kgalagadi and were not restricted to the Nossob or Auob riverbeds. Most lions were caught at night following the method of Smuts et al. (1977) where bait was placed at various locations throughout the park, selected at random or when there were fresh signs of lion activity, during the capture operation. Lions drawn to the bait were marked. A total of 25 sites were visited during the capture phase of which $88 \%$ were successful. There were no repeat attempts on consecutive nights although additional lions were caught after repeat attempts at eight (32\%) sites. There was no pre-baiting of sites although taped calls of a blue wildebeest calf in distress and spotted hyaena were played at the sites. A few lions $(n=7,10 \%)$ were caught during daylight after following fresh tracks, or during opportunistic encounters on routine patrols.

Symbols approximately $10 \mathrm{~cm}$ in length were branded onto the right shoulder or rump of each animal caught, ensuring that each was individually recognizable. Not all individuals encountered during the capture phase were caught, partly as a result of the logistical problem with handling large groups of lions. Furthermore, animals younger than nine months (small and medium cubs) were also not caught as the study aimed to assess the status of the subadult and adult population. All marked lions were sexed and aged according to tooth eruption, replacement and wear described by Smuts et al. (1978). Semen samples were collected from four adult males and examined for the presence of spermatozoa, while genetic material was taken from 35 individuals to provide some insight into the viability and genetic heterozygosity of the population (Wildt \& Bush, pers. comm.).

Between 19 December 1996 and 11 February 1997 (recapture sample 1) and 20 July and 20 August 1997 (recapture sample 2) attempts were made by field staff in the KGNP to note brands, group size, sex and age composition of all lions sighted on routine patrols and dedicated lion monitoring excursions within the park (Fig. 2). From these data an estimate of the population size was made using a series of Lincoln-Petersen estimates. A number of the models, such as the Jolly-Seber Model, developed for open populations and time-series recapture analyses (Caughley 1977; Pollock et al. 1990; Nichols 1992) were 


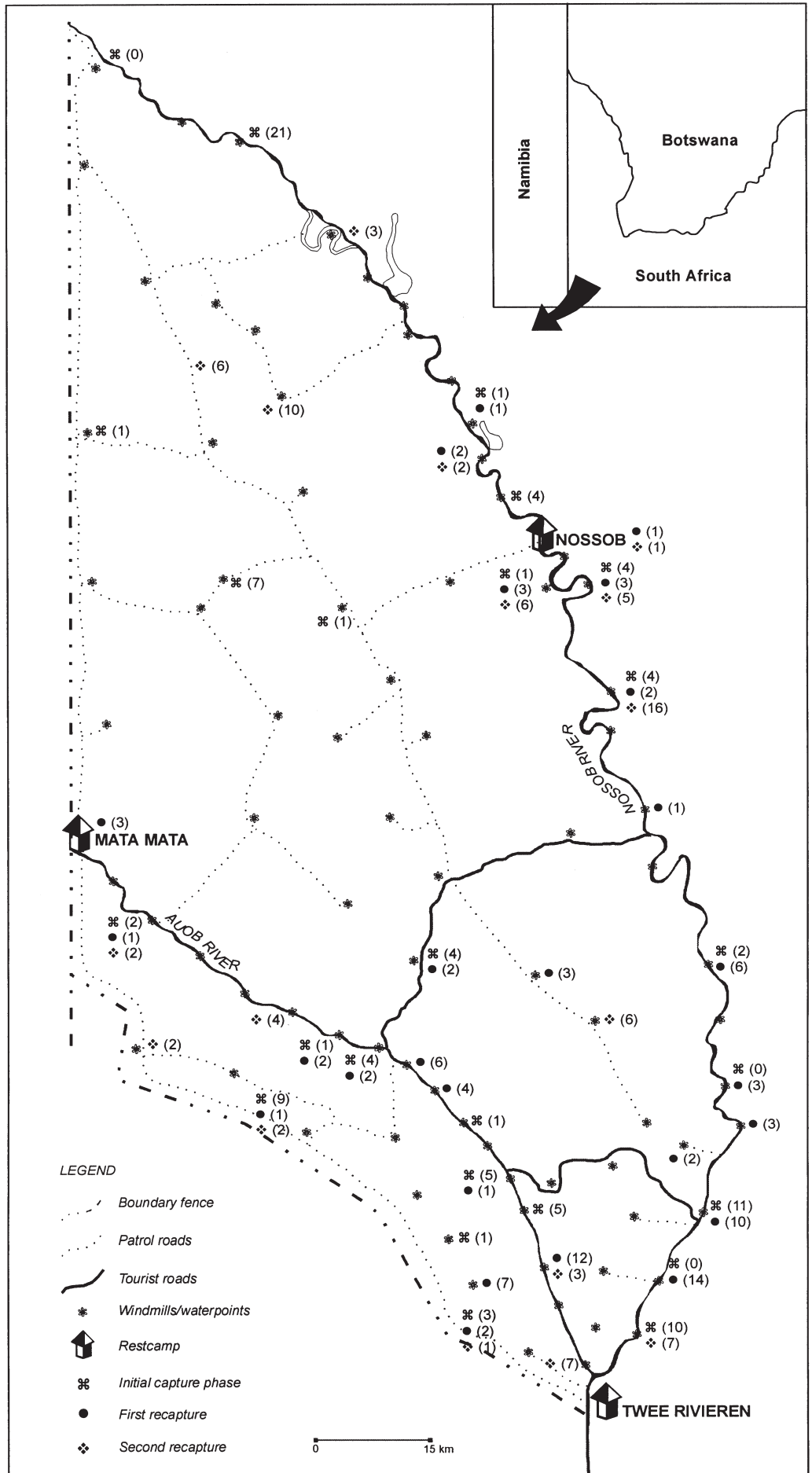

Fig. 1. Diagrammatic representation of the study area showing the distribution and numbers of lions inclusive of cubs (in brackets) during the initial capture and subsequent recapture samples of the study. Localities are given in relation to the nearest waterhole, pan or restcamp from where the lions were recorded. 


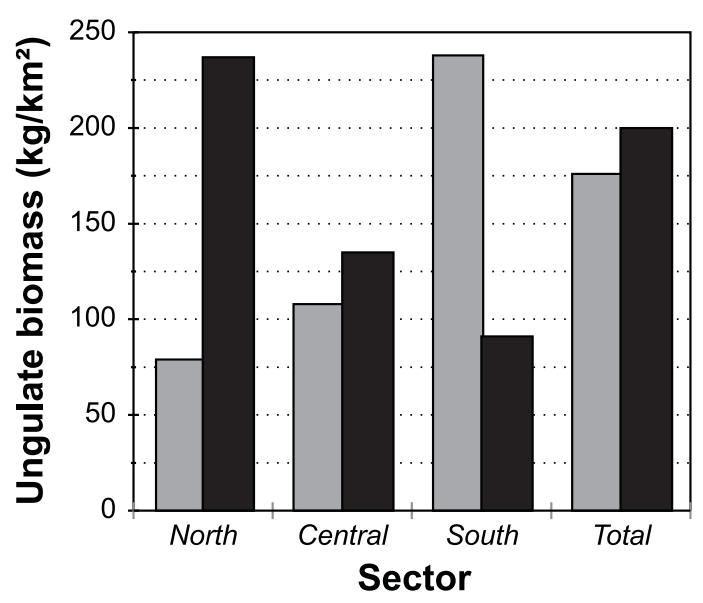

1974

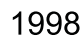

Fig. 2. Prey biomass and distribution among the three sectors of the southern KTP (previously Kalahari Gemsbok National Park). Prey species used in the biomass calculations include springbok, gemsbok, red hartebeest, blue wildebeest, and eland. Biomass figures (see Coe et al. 1976) were derived from population estimates of large mammals calculated from aerial surveys and historical ground count records.

inappropriate in the current study as a result of the extended capture and recapture phases.

Several assumptions made by the LincolnPetersen estimation procedure are often violated in wildlife management studies (Begon 1979; Pollocket al. 1990; Caughley \& Sinclair 1997). These are: 1 ) the population is closed to additions (birth or immigration) and deletions (death or emigration); 2) no marks are lost or overlooked by observers; 3) all animals are equally 'catchable' without being influenced by previous capture (random sampling).

As the study focussed on lions older than nine months (subadults and adult), and given that lions are a relatively long-lived species, with the study being undertaken over a relatively short period, we restricted the chances of bias resulting from additions or deletions and assumed demographic closure for the Kgalagadi lion population (Begon 1979; Pollock et al. 1990; Nichols 1992; Caughley \& Sinclair 1997). Due to the nature of the marking operations during capture, tag loss is negated. However, overlooking these marks in subsequent recapture operations may be a factor that generates bias in the estimation. Unfortunately equal catchability among marked and unmarked individuals was difficult to establish as Mills et al. (1978) noted in their initial assessment of the population. However, Pollock et al. (1990) suggest that in cases where different sampling methods were used in the capture and recapture phases there should be little concern with trap response and the heterogeneity of capture probabilities. A similar situation exists in the present study. Leslie's test (Chi-square) for equal catchability (Caughley 1977) was applied to each recapture sample to determine whether or not there was in fact a random sampling of the marked population based on the number of times individuals were observed in each recapture sample. In addition $z$-tests incorporating Yates' correction for continuity were run to test for randomness of capture between the numbers of marked and unmarked individuals in each recapture sample (Zar 1984).

Observers were periodically unsure of whether lions were marked or unmarked and this equates to the theoretical problem of 'tag-loss' and is a source of bias. Therefore, such undetermined animals were excluded from the analyses. Duplicate (repeat) sightings of the same individuals within each recapture sample were similarly excluded from the analyses.

The software program NOREMARK (White 1996a), which has been specifically designed to estimate population sizes from capture-recapture surveys (White 1996b), was used in order to verify our Lincoln-Petersen estimates. Of the four procedures available in NOREMARK, the MintaMangel (Minta \& Mangel 1989, cited in White 1996a) and Bowden's (Bowden 1993, cited in White 1996a) estimation procedures were selected, as these two estimators are not dependant on the assumption that each animal in the population has the same capture probability during any particular sampling occasion (White 1996a). The only assumptions made by NOREMARK are that the number of marked animals is known and that marked animals are a representative sample from the population. We assume that the 68 individuals marked are representative of the population as this comprises almost $50 \%$ of the total population based on previous estimates.

\section{RESULTS}

\section{Population estimates}

The minimum number of lions in the population can be estimated directly from the numbers marked and recorded during capture operations (Fig. 1). Over the initial two-month capture period, a total of 68 lions were individually 
Table 1. Lion population estimates from the southern KTP (previously KGNP) as determined using the Lincoln-Petersen estimation procedure after removing the numbers of cubs, undetermined animals and duplicate sightings. Bowden and Minta Mangel estimators are derived from the programme NOREMARK (White 1996b).

\begin{tabular}{lccccrr}
\hline & Total No. & Marked & Unmarked & Estimate & S.E. & $95 \%$ limits \\
\hline Recapture sample 1 & & & & & & \\
Total & 97 & 50 & 33 & 131 & 12.5 & $106-156$ \\
Total (after removals) & 54 & 33 & 21 & 110 & 11.5 & $87-133$ \\
$\begin{array}{l}\text { Bowdens estimator } \\
\text { Minta-Mangel estimator }\end{array}$ & & & & 92 & & $78-109$ \\
Recapture sample 2 & & & & & & $84-113$ \\
Total & 83 & 23 & 38 & 238 & 40.2 & $159-317$ \\
Total (after removals) & 32 & 17 & 15 & 125 & 19.3 & $87-163$ \\
Bowdens estimator & & & & 107 & & $83-138$ \\
Minta-Mangel estimator & & & & 108 & & $92-141$ \\
\hline
\end{tabular}

marked (47 females and 21 males). In addition to these animals, a further 32 were positively identified as being unmarked while the marking of three could not be determined. The minimum number of lions present in the KGNP is therefore between 100-103 animals assuming that none of the unmarked animals were duplicated during the twomonth period.

\section{Lincoln-Petersen estimates}

Lincoln-Petersen estimates were made for each recapture sample. The estimates focused only on the adult and subadult lion population and excluded all cubs, duplicate sightings and undetermined individuals (tag loss) from the calculations. During the first recapture sample, 36 groups of lion were seen comprising 97 individuals (mean group size $=2.7$, range $=1-11$ ), of which 50 were marked (including 17 duplicate sightings), 33 were unmarked (including 12 cubs) and 14 were indeterminable. Substitution of the resultant values into the modified Lincoln-Petersen equation

$$
N=\frac{M(n+1)}{R+1}
$$

where $M$ represents the initial sample population captured and marked, $n$ is the number of individuals recaptured and $R$ is the number of marked animals in the first recapture sample, gives a population estimate of $110 \pm 11.5$ (S.E.) individuals (95\% confidence limits $=87-133$ ). Substitution into the equation of the data obtained during the second recapture sample in which 24 groups were seen containing 83 individuals (mean group size $=3.5$, range $=1-12$ ) of which 23 were marked (including six duplicate sightings), 38 were unmarked (including 23 cubs) and 22 were indeterminable, gave a population estimate of $125 \pm 19.3$ (S.E.) individuals (95\% confidence limits $=87-163)$ (Table 1). Estimates derived from NOREMARK were comparable with the LincolnPetersen estimates, while the narrower confidence intervals of the NOREMARK estimates suggests greater precision.

Within the sample of marked individuals $(n=$ 68) there was a non-random resighting probability, with a large number of marked animals not being seen in either of the recapture samples. Therefore, neither recapture phase satisfies the third assumption of the Lincoln-Petersen estimation procedure that there is equal 'catchability' among the marked sample of animals (recapture sample 1: $\chi^{2}=124.37$, d.f. $=67, P<0.001$; recapture sample $2: \chi^{2}=88.40$, d.f. $=67, P<0.05$ ). However, when the 'catchability' of marked versus unmarked animals is analysed using $z$-tests it is evident that there is a significant difference in the numbers of marked and unmarked individuals for recapture sample $1(z=2.919$, d.f. $=1, P=<0.05)$ but not for recapture sample $2(z=0.415$, d.f. $=1$, $P=0.678)$. Even though there were significantly more marked animals recorded in the first recapture sample, the fact that there were no significant differences between marked and unmarked animals in the second recapture sample suggests that the resighting of lions may indeed be random.

\section{Population characteristics}

The sex ratios and age distribution of lions seen (excluding all duplicate sightings but inclusive of unmarked and unidentified individuals) during the initial capture and the two recapture samples are summarized in Table 2. Within the adult and subadult groupings of the marked population 
Table 2. Sex and age distribution of lions seen during resighting operations in the KGNP. Total numbers of each category are given while percentage figures are given in brackets. The analysis includes all unmarked and unidentified individuals while excluding duplicate sightings of specific individuals.

\begin{tabular}{lrrrrrrr}
\hline Phase & Adult male & Adult female & Subadult & Subadult & Large cub & Medium cub Small cub \\
\hline Initial & $15(15)$ & $51(50)$ & $4(4)$ & $9(9)$ & $16(16)$ & $2(2)$ & $5(5)$ \\
1 & $9(12)$ & $41(55)$ & $6(8)$ & $6(8)$ & $1(1)$ & $3(4)$ & $9(12)$ \\
2 & $13(17)$ & $31(40)$ & $6(8)$ & $1(1)$ & $3(4)$ & $13(17)$ & $10(13)$ \\
Average & $12(14)$ & $41(49)$ & $5(6)$ & $5(6)$ & $7(8)$ & $6(7)$ & $8(10)$ \\
\hline
\end{tabular}

$49 \%$ of the population was over eight years of age, $14 \%$ were between six and seven years, $22 \%$ were between three and four years while $16 \%$ were below two years of age. The adult sex ratio during the initial capture was 3.4 females per male while the sex ratio among subadults was uniform. Combination of both the adult and subadult categories reduces this ratio to 2.7:1. Adult females dominated both recapture samples although the representation of cubs and adult males was considerably higher in the second recapture sample. Between the initial capture and the second recapture sample there was no significant change in the proportion of subadults in the population $(z=$ $0.49, P=0.624)$. However, there was a significantly greater proportion of large cubs in the population during the initial capture $(z=2.82, P<0.005)$, whereas a significantly greater proportion of medium and small cubs were seen during subsequent recapture samples $(z=5.84, P<0.0001)$ (Table 2$)$, perhaps because lions were less likely to bring smaller cubs to bait. The average representation of adults, subadults and cubs in the population was in the ratio of 5.25:1:2.08.

\section{DISCUSSION}

From the estimates used (i.e. both LincolnPetersen and NOREMARK estimates), the lion population estimate (adults and subadults) from the southern section of the KTP averages 100 (range 83-118) individuals for the first recapture sample and 113 (range 87-147) for the second recapture sample. Assuming that the survey biases can be adequately accounted for through adjustment of the figures used in the calculation of the estimate, a minimum population total of 107 adult and subadult lions is estimated, which is lower than the previous estimate of 140 animals by Mills et al. (1978). Mills et al. (1978) suggested that their figure may have underestimated the population as a result of surveys being restricted to certain areas of the KGNP, which essentially pre- cluded the sighting of lion prides in more remote or inaccessible areas. Although the interconnecting dune country makes up roughly $96 \%$ of the southern KTP, the efforts during capture and recapture exercises in the current study were similar within the riverbeds and dunes. Thirty percent and $70 \%$ of the captures were made in the dunes and riverbeds respectively, comparable to the $18-33 \%$ and $67-82 \%$ of subsequent recapture samples in these respective habitats.

Pollock et al. (1990) suggest that where different sampling methods are used, as in the current study, there should be little concern with trap response or heterogeneity of capture probabilities. Furthermore, should marking increase the chances of resighting then the proportions of marked to unmarked animals in the samples should be high, in which case the population would be underestimated. The significant differences observed in the proportions of marked to unmarked animals in the first recapture sample could therefore be an underestimate whereas the lack of any differences in the second recapture sample suggest a more appropriate estimate. Given that the proportion of marked to unmarked individuals in the two recapture samples were different, capture probabilities appear to be independent for each sample (see Pollock et al. 1990). We therefore assume that there is little bias associated with the heterogeneity of capture probabilities in the current study.

Certain marked individuals were recorded more often than others which may be because recapture efforts were concentrated in the riverbeds while the dune areas were relatively neglected. Furthermore, recapture exercises were only conducted during the day whereas initial capture of the animals took place largely at night. It is therefore possible that many of these marked individuals may not have been recaptured purely due to the methods employed.

Clearly the recapture of lions in the KGNP is largely dependent on the home ranges of the 
various prides, and those whose ranges overlap with the dry riverbeds may have a greater chance of being seen. Mills et al. (1978) have previously shown that more lion sightings are made along these riverbeds than in the connecting dune areas, which suggests that lions are easier to see in these areas and may well be spending more time in these habitats, probably attracted to the higher prey densities.

Lion density in the KGNP was estimated to be 1.2 adult and subadult lions $/ 100 \mathrm{~km}^{2}$. This figure is considerably lower than estimates from the majority of other African conservation areas (Mills et al. 1978). Mills (1995) estimated the Kruger National Park population density to range between 3.3-9.6 adult and subadult lions $/ 100 \mathrm{~km}^{2}$ in variable climatic conditions. In other, more mesic African savanna woodland habitats Creel \& Creel (1997) estimated the lion density of a hunted population to be between 8 and 13 adults $/ 100 \mathrm{~km}^{2}$, while Yamazaki (1996) estimated densities of between five and six adult and subadult pride females/ $100 \mathrm{~km}^{2}$ or $12-13$ lions $/ 100 \mathrm{~km}^{2}$ if calculated for all pride members. It is therefore apparent and not surprising that lion density is considerably lower in xeric habitats where primary production is lower and more erratic and the availability of water sparser, thus affecting the distribution and density of prey species. When compared to another semi-arid savanna system such as the Etosha National Park where the density of lions ranges between 1.6 and 2.0 adults and subadults $/ 100 \mathrm{~km}^{2}$ (Stander 1991), the density of lions in the KGNP is only slightly lower.

\section{CONCLUSIONS AND RECOMMENDATIONS}

Notwithstanding the shortcomings of the LincolnPetersen estimation approach to lion surveys, the capture-recapture method is a satisfactory method for lion population assessments in large areas such as the southern Kalahari. It appears that the lion population of the southwestern Kgalagadi has shown a marginal decline over the past 20 years, with a population estimate in the region of 110-140 animals. However, there appear to be some marked differences in the sex composition of the population which may have implications for the future viability of the population. Additional concerns arise when considering the density of the population which is substantially lower than most other African conservation areas. The population effects of skewed sex ratios and smaller group sizes may be compounded purely as a result of the small and isolated nature of the population and remain to be quantified. Isolation effects and intraspecific interactions require additional attention in view of the fact that apparently suitable lion habitat extends uninterrupted from the southwestern Kgalagadi district into the Central Kalahari Game Reserve.

\section{ACKNOWLEDGEMENTS}

The South African National Parks, in particular the Park Manager and staff of the Kalahari Gemsbok National Park, are thanked for logistical support provided for the duration of this study. We are indebted to a number of people who were of valuable assistance in the field particularly, Dave Wildt, Mitch Bush, Giel de Kock, Nardus du Plessis, Tienie Visser, and Rudi Williams who assisted with both marking and resighting operations.

\section{REFERENCES}

BEGON, M. 1979. Investigating Animal Abundance. Edward Arnod, London.

BOTHMA, J. DU P., VAN ROOYEN, N., THERON, G.K. \& LE RICHE, E.A.N. 1994. Quantifying woody plants as hunting cover for southern Kalahari leopards. Journal of Arid Environments 26: 273-280.

BOTHMA, J. du P., KNIGHT, M.H., LE RICHE, E.A.N. \& VAN HENSBERGEN, H.J. 1998. Range size of southern Kalahari leopards. South African Journal of Wildlife Research 27: 94-99.

BOWDEN, D.C. 1993. A Simple Technique for Estimating Population Size. Colorado State University, Fort Collins.

CASTLEY, J.G. \& KNIGHT, M.H. 1997. Fixed wing surveys of the Kalahari Gemsbok National Park, South Africa, and the Gemsbok National Park, Botswana, April 1996/1997. Internal report, South African National Parks, Kimberley.

CASTLEY, J.G. \& KNIGHT, M.H. 1998. Fixed-wing aerial survey of the Kalahari Gemsbok National Park, South Africa, April 1998. Internal report, South African National Parks, Kimberley.

CAUGHLEY, G. 1977. Analysis of Vertebrate Populations. John Wiley, New York.

CAUGHLEY, G. \& SINCLAIR, A.R.E. 1997. Wildlife Ecology and Management. Blackwell Scientific, Oxford.

COE, M.J., CUMMING, D.H.M. \& PHILLIPSON, J. 1976. Biomass and production of large African herbivores in relation to rainfall and primary production. Oecologia 22: 341-354

CREEL, S. \& CREEL, N.M. 1997. Lion density and population structure in the Selous Game Reserve: evaluation of hunting quotas and offtake. African Journal of Ecology 35: 83-93.

HOLT-BIDDLE, D. 1996. Weather extremes cause wildlife woes in South Africa. African Wildlife Update 5(4): 1-8.

KNIGHT, M.H. 1991. Ecology of the gemsbok Oryx gazella 
gazella (Linnaeus) and blue wildebeest Connochaetues taurinus (Burchell) in the southern Kalahari. Ph.D. thesis, University of Pretoria, Pretoria.

KNIGHT, M.H., KNIGHT-ELOFF, A.K. \& BORNMAN, J.J. 1987. The importance of borehole water and lick sites to Kalahari ungulates. Journal of Arid Environments 15: 269-281.

MILLS, M.G.L. 1984. Prey selection and feeding habits of the large carnivores in the southern Kalahari. Koedoe Supplement 281-294.

MILLS, M.G.L. 1989. Kalahari Hyaenas. Unwin Hyman, London.

MILLS, M.G.L. 1995. Notes on wild dog Lycaon pictus and lion Panthera leo population trends during a drought in the Kruger National Park. Koedoe 38: 95-99.

MILLS, M.G.L. 1996. Methodological advances in capture, census, and food-habits studies of large African carnivores. In: Carnivore Behaviour, Ecology, and Evolution, Vol. 2, (ed.) J. Gittleman, pp. 223-242. Cornell University Press, Ithaca and London.

MILLS, M.G.L. \& RETIEF, P.F. 1984a. The effect of windmill closure on the movement patterns of ungulates along the Auob riverbed. Koedoe Supplement 107-118.

MILLS, M.G.L. \& RETIEF, P.F. 1984b. The response of ungulates to rainfall along the riverbeds of the southern Kalahari, 1972-1982. Koedoe Supplement 129-141.

MILLS, M.G.L., WOLFF, P., LE RICHE, E.A.N. \& MEYER, I.J. 1978. Some population characteristics of the lion
Panthera leo in the Kalahari Gemsbok National Park. Koedoe 21: 163-171.

MINTA, S. \& MANGEL, M. 1989. A simple population estimate based on simulation for capture-recapture and capture-resight data. Ecology 70: 1738-1751.

SMUTS, G.L., WHYTE, I.J. \& DEARLOVE, T.W. 1977. A mass capture technique for lions. East African Wildlife Journal 15: 81-87.

SMUTS, G.L., ANDERSON, J.L. \& AUSTIN, J.C. 1978. Age determination of Panthera leo. Journal of Zoology (London) 185: 115-146.

STANDER, P.E. 1991. Demography of lions in the Etosha National Park, Namibia. Madoqua 18: 1-9.

VERLINDEN, A. 1998. Seasonal movement patterns of some ungulates in the Kalahari ecosystem of Botswana between 1990 and 1995. African Journal of Ecology 36: 117-128.

WHITE, G.C. 1996a. Program NOREMARK Software Reference Manual. Department of Fisheries \& Wildlife, Colorado State University, Fort Collins.

WHITE, G.C. 1996b. NOREMARK: population estimation from mark-resighting surveys. Wildlife Society Bulletin 24: 50-52.

YAMAZAKI, K. 1996. Social variation of lions in a maledepopulated area in Zambia. Journal of Wildlife Management 60: 490-497.

ZAR, J.H. 1984. Biostatistical Analysis, 2nd edn. PrenticeHall, New Jersey. 